\title{
Making medicines that children can take
}

\section{A J Nunn}

\section{The role of the pharmacist}

T he Medicines Act of 1968 and subsequent UK and European legislation established the process of licensing (now authorisation) to assure the safety, efficacy, and quality of medicines. While the majority of medicines for adults are licensed, many medicines used for children are not licensed for purpose (they are used "off-label") or have not been licensed at all (unlicensed).

\section{WHY MUST PHARMACISTS MAKE ORAL MEDICINES FOR CHILDREN?}

Suitable licensed medicines are usually available for common problems such as infections but there are few, if any, available for less common conditions such as hypertension. The success of financial incentives to encourage pharmaceutical companies to licence medicines for children in the USA would suggest that the main reason for the dearth of licensed children's medicines is profit related. There may also be other reasons related to perceived and actual difficulties in conducting clinical trials, such as recruitment and consent and the cost of developing paediatric formulations. There is also a worrying trend for UK companies to discontinue licensed paediatric formulations (but not the adult versions) because of low demand (for example, dantrolene, griseofulvin, naproxen, and nitrofurantoin suspensions). The Department of Health and the Association of the British Pharmaceutical Industry (ABPI) has agreed a voluntary system for early notification of discontinuations to allow time for alternative arrangements to be made. ${ }^{1}$ If not discontinued globally it is possible (but expensive) to import the product, but it is then considered to be an unlicensed medicine in the UK. If totally discontinued it may be necessary for the pharmacist to prepare extemporaneously if therapeutic alternatives are unsuitable. Extemporaneous dispensing is the compounding of ingredients to prepare a medicine for an individual patient.

Several surveys have now established the frequency of use of off-label and unlicensed medicines in different situations. Thus about $11 \%$ of medicines used for children in UK general practice are off-label or unlicensed ${ }^{2}$; figures are 25\% in hospital general wards, ${ }^{34} 40 \%$ in paediatric intensive care units, ${ }^{5}$ and $80 \%$ in neonatal intensive care units. ${ }^{6}$ The situation in other European countries is similar. ${ }^{7-14}$ The need to use off-label and unlicensed medicines in paediatric practice has been recognised in a statement from the joint Medicines Committee of the Royal College of Paediatric and Child Health (RCPCH) and the Neonatal and Paediatric Pharmacists Group (NPPG) that was sent to all NHS Trusts. ${ }^{15}$ Information on the use of these medicines is available in the peer reviewed national formulary Medicines for children, ${ }^{16}$ or from sources such as the national medicines information resource (DIAL) at Alder Hey Children's Hospital in Liverpool (www.dial.org.uk).

Since most authorised or licensed oral medicines are intended for adults they are presented as tablet or capsule formulations, often in a unit intended as a single adult dose. Some are available as liquids, but have a concentration unsuitable for measuring the dose and administering to the newborn or young children. The size of the dose administered from a children's medicine needs to be variable throughout childhood in proportion to body weight, body surface area, or age, generally making solid oral dose forms inappropriate. In addition, many young children are unable to swallow tablets or capsules and inappropriate persistence in administration risks inhalation.

\section{PREPARING SUITABLE MEDICINES TO BE USED OFF-LABEL}

If the licensed adult dosage form is inappropriate for paediatric use the pharmacist must prepare a suitable preparation extemporaneously. Crushing the licensed tablet formulation or opening the capsule and using the contents may achieve this. The resulting powder may be dissolved or suspended with various excipients to produce an oral liquid medicine or may be redistributed in smaller strength capsules or powder papers (sachets), sometimes after dilution with lactose or a similar material. A licensed injection, for example midazolam or dinoprostone, may be the primary ingredient for an oral liquid medicine.

Oral liquids are comparatively quick to prepare and can allow flexibility in dosage taken from a single strength preparation by accurately measuring the volume required using a syringe or pipette designed for oral administration. However, oral liquids may be difficult to formulate to ensure palatability, and physical, chemical, and microbial stability. The formulations may contain excipients (especially preservatives) that produce adverse reactions in some babies or children.

Small strength capsules are usually opened before administration and the contents administered with liquid or food. In general, if stored under suitable conditions away from moisture, oral capsules and powders should have greater stability than oral liquids, but are more time consuming to prepare. They are fixed dosage forms, so many different strengths may be required to satisfy the varying dosage requirement of children of different ages.

Appropriate preparations may also be made from chemical ingredients rather than by manipulating licensed formulations (tablets or capsules).

Tablets are sometimes cut into smaller segments (halves or quarters) in the pharmacy or on the hospital ward to obtain appropriately sized dosage units for children (for example, aspirin, captopril). These segments are subsequently crushed and administered with liquid or food. Segments from tablets are quick to cut, and probably have similar stability to the original tablet, but they cannot be cut with great accuracy of dose. ${ }^{17} 18$ Some tablets for adults dissolve or disperse in water (for example, sildenafil for pulmonary hypertension). If dissolved in a known quantity of water an appropriate proportion can be measured containing the required dose. However, some tablets disperse rather than dissolve, making accurate fractional dosing more difficult; this deserves further study.

It may sometimes be appropriate to administer injection solutions (for example, labetalol) by the enteral route. The practitioner should be assured that the intravenous form of the drug will be absorbed by the enteral route, that the $\mathrm{pH}$ of the solution will be tolerated, and that excipients will not be harmful. Taste and volume may be problematic and the cost of using an expensive injectable form orally must be taken into account. ${ }^{19}$

When licensed medicines are manipulated to produce a different formulation, the resulting product is an unlicensed formulation even though the use to which it is put is "off-label". This legal technicality is unlikely to cause any greater concern to the paediatrician but 
the pharmacist should be aware of responsibility for the quality of the product.

\section{PREPARING UNLICENSED MEDICINES}

Medicines without any authorisation or licence are used when no pharmaceutical manufacturer has sought a Marketing Authorisation or Product Licence for a medicine for any condition. These medicines may be for rare diseases such as inborn errors of metabolism (for example, arginine or sodium benzoate solutions) or neonatal illness (for example, caffeine citrate) or they may be long established medicines such as chloral hydrate and flecainide. Unlike off-label medicines some may never have been submitted to the scrutiny of any medicines licensing process.

Products may be prepared from ingredients of pharmacopoeial standard or from chemicals without official standards purchased from a variety of sources and often not sold as ingredients for the preparation of medicines. These chemicals (and any impurities) should be identified and analysed to establish their quality for use as medicines.

With the advent of orphan drugs regulations in the European Community (EC) there are now financial incentives for manufacturers to licence products for rare diseases (for example, carbamyl glutamate, sodium phenylbutyrate). One paradoxical adverse outcome is the inevitable additional cost of licensing which is thought by some to be disproportionate. ${ }^{20}$ Lack of funding may mean that attempts are made to continue using chemicals or extemporaneous products rather than paying the higher cost of the licensed, orphan drug.

\section{SCALE OF PREPARATION}

Some extemporaneous dispensing takes place on a large scale. This may be in hospital pharmacies or laboratories operating to Good Manufacturing Practice (GMP) standards ${ }^{21}$ and the activity may be inspected and licensed by medicines agencies. (In the UK the Medicines Control Agency (MCA) may grant a manufacturing licence and products from these laboratories are referred to as "specials".) These laboratories may also be companies operating in the commercial sector or they may be large hospital pharmacies or health service syndicates (such as Pharmacie Centrale des Hôpitaux de Paris). The purchasing pharmacist (and not the prescriber) is responsible for the quality of products obtained from such facilities and should purchase against a product specification and test the products, taking advice from NHS quality assurance pharmacists.

Table 1 Useful sources of information about paediatric formulations

Grassby PF. UK formulary of extemporaneous preparations. Penarth: Paul F Grassby, 1995 (ISBN 0952488000 0. www.npqa.org)

Woods DJ. Formulation in pharmacy practice, 2nd. www. pharminfotech.co.nz/emixt

Nahata MC, Hipple TF. Pediatric drug formulations, 4th edn. Cincinnati: Harvey Whitney Books Co., 2000 (ISBN 0-929375-23-8)

Trissel LA. Stability of compounded formulations. Washington: American Pharmaceutical Association, 2000 (ISBN 1-58212-007-2)

\section{FORMULATION AND STABILITY}

Extemporaneous preparations may be made according to a formulation published in a pharmacopoeia or in some other published work of reference, or the formulation may have been developed locally (see table 1). The research undertaken to establish the suitability of the formulation and its physical, chemical, and microbial stability may be extensive, but such work may not be undertaken at all. In a recent unpublished UK survey it was noted that $54 \%$ of 112 paediatric extemporaneous formulations had inadequate data on shelf life. It is important that pharmacists accept responsibility for the quality of the formulation, stability of the product, and the quality of ingredients used.

\section{RISK}

Extemporaneous dispensing is not without risk. There are no published standards for the process in the UK or many European countries. In contrast to manufactured medicines there is little or no opportunity for the pharmacist to apply analytical procedures to assure the quality of the product. Frequently the only assurance of quality will be a work sheet recording amounts of ingredients with facility for operators to indicate that ingredients have been added and/or checked. Errors in preparation, some of them with potentially serious consequences, have been noted. ${ }^{22}$ When prepared on a large scale ("specials") there should be adequate opportunity to include quality assurance measures, including analysis of the finished product. In general, and if products have a sufficiently long shelf life, such preparation should be preferred to one-off or small scale extemporaneous dispensing.

Sometimes extemporaneous preparation is undertaken, even though an appropriate preparation is licensed in another country with licensing arrangements similar to those of the UK and Europe (for example, North America, Australia). Appropriate paediatric preparations may even be licensed in one European country but not others (for example, nifedipine drops, folic acid syrup). It is possible to import such preparations into the UK (or into and between European countries, although regulations and ease of importation or movement vary) through a recognised pharmaceutical importer. Such companies have extensive databases showing the worldwide availability of medicines but can only advertise their service and not products to avoid infringing the Medicines Act. Importers of medicines should ensure that professional and patient information is translated into the local language. Although "unlicensed" in the importing country, since these medicines have been scrutinised by a licensing agency and prepared with Good Manufacturing Practice, the risks in using them should be lower than using extemporaneously prepared medicines.

\section{INTERFACE ISSUES}

Patients may find it more difficult to obtain extemporaneous preparations from their community pharmacist who may not have ready access to the ingredients required. Some will request the preparation to be made by a "specials house" and there could be a delay. Hospital pharmacists must ensure that the formula and instructions are accurately communicated to the prescribing general practitioner and chosen community pharmacist. For some formulations it may be preferable to maintain supply from the hospital pharmacy.

It may also be more difficult to obtain imported medicines in the community. Again, the hospital pharmacist should supply information to the community prescriber and dispenser and ensure continuity of supply.

General practitioners may be reluctant to prescribe off-label or unlicensed medicines if they have insufficient information to assume clinical and prescribing responsibility for a course of treatment.

The Patient Information Leaflet (PIL; which must be supplied with dispensed medicines) may contradict the use to which an off-label medicine is put. However, for extemporaneous preparations there will not be an official PIL. Some hospital pharmacists have written information leaflets for specific extemporaneous preparations, and the generic leaflets from Medicines Committee of RCPCH/ NPPG provide helpful information about why some medicines must be prepared specially. ${ }^{23}$ 


\section{EUROPEAN PERSPECTIVE}

Surveys of European hospital pharmacists undertaken on behalf of the European Society for Clinical Pharmacy (ESCP) have shown common problems within the EC. However, the method of extemporaneous dispensing varies between countries. For example, while the UK, Ireland, Norway, and Sweden tend to prepare oral liquids, France and Spain tend to prepare capsules, while Finland and Italy tend to prepare powders. The same drug may be prepared in different forms and in many different strengths and the same drug may be prepared in the hospitals of several European countries but to different formulations. Some of the preparations prepared extemporaneously in one country are available as suitable licensed medicines in another. There is limited knowledge of the availability of licensed medicines for import, and importation or movement into and between some European countries is difficult or impossible.

\section{WHAT NEEDS TO BE DONE?}

Paediatricians may not always be aware that many of the medicines they prescribe are prepared extemporaneously and that the quality of these medicines may not be assured. Pharmacists must recognise that it is their responsibility to provide these assurances. It is important that all concerned identify extemporaneous preparation as a necessary and important method of making appropriate medicines available for children. However, it is also important that they are aware of the potential problems. Pharmacists and paediatricians should work together to ensure that suitable licensed preparations are used when available. This may include using pharmacological alternatives or importing preparations licensed in other countries. Extemporaneous preparation should only be used if there are no alternatives.

There is a need for national standards for extemporaneous dispensing to ensure that medicines of the best quality are consistently produced. Medicines prepared extemporaneously should be rationalised for formulation and strength and their standards assured by monographs in official publications like the British or European Pharmacopoeias. If there is insufficient data to support the formulation or its stability, this data should be gathered in a way that avoids duplication of effort. Surveys in the UK and other countries have indicated where deficiencies lie, but resources must be identified to undertake the research required. The developing European paediatric pharmacology and therapeutics research network must also have a pharmaceutical focus to ensure that medicines studied are appropriately formulated.
Children should have access to modern, licensed medicines. The European Commission has shown its intention to improve the situation by publishing a consultation document "Better medicines for children". ${ }^{24}$ It may take many years to see a significant improvement. In the meantime, the Committee for Proprietary Medicinal Products (CPMP) and several European medicines agencies are attempting to improve the situation within current legislation by reviewing and publicising the research required for specific off-label drugs, including the need for appropriate paediatric formulations. ${ }^{25}$

Time, expertise, and facilities in hospital pharmacies limit the type of preparations prepared extemporaneously. Modern dosage forms using, for example, "melt" technology and sustained release technology are rarely available. Pharmaceutical companies have appropriate facilities and should be encouraged to make modern dosage forms available for children. If they market a suitable licensed paediatric preparation in one country they must be encouraged to market in all countries. There should be free movement of licensed medicines between European countries and information on the availability of medicines for import should be easily available. Medicines agencies should cooperate to improve the situation and reconsider some of the rules that seem to work against the best interests of children.

\section{CONCLUSIONS}

Extemporaneous dispensing is currently necessary to ensure that children can be treated with appropriate medicines, but we do not have the assurances of quality available with licensed medicines. Pharmacists could do much to improve the situation until anticipated legislation increases the availability of licensed medicines. Since many of the problems are common to all European countries there are opportunities to collaborate through established and developing networks such as the ESCP and the European Society for Developmental, Perinatal and Paediatric Pharmacology (ESDP).

Shirkey described children as "therapeutic orphans" more than 30 years ago. ${ }^{26}$ How little things have changed!

Arch Dis Child 2003;88:369-37

Author's affiliation

A J Nunn, Department of Pharmacy, Alder Hey Children's Hospital, Liverpool, UK

Correspondence to: $\mathrm{Mr}$ A J Nunn, Director of Pharmacy, Alder Hey Children's Hospital, Eaton Road, Liverpool L12 2AP, UK;

Tony.Nunn@rlch-tr.nwest.nhs.uk

\section{REFERENCES}

1 DOH/ABPI. www.doh.gov.uk/

discontinuedmedicines/index.htm.
2 Mclntyre J, Conroy S, Avery A et al. Unlicensed and off label prescribing of drugs in general practice. Arch Dis Child 1999;83:498-501.

3 Turner S, Nunn AN, Fielding K, et al. Adverse drug reactions to unlicensed and off-label drugs on paediatric wards: a prospective study. Acta Paediatr 1999;88:965-8.

4 Turner S, Longworth A, Nunn AJ, et al. Unlicensed and off label drug use in paediatric wards: prospective study. BM 1998:316:343-5.

5 Turner S, Gill A, Nunn A, et al. Use of "off label" and unlicensed drugs in a paediatric intensive care unit. Lancet 1996;347:549-50.

6 Conroy S, McIntyre J, Choonara I. Unlicensed and off label drug use in neonates. Arch Dis Child Fetal Neonatal Ed 1999;80:F142-4.

7 Seyberth HW. Aktuelle probleme der klinischen pharmacologie im kindesalter. Kinderarzt 1984;15:309-14.

8 Chalumeau M, Tréluyer JM, Salanave B, et al. Off label and unlicensed drug use among French office based paediatricians. Arch Dis Child 1999;83:502-5.

9 Conroy S, Choonara I, Impicciatore P, et al. Survey of unlicensed and off label drug use in paediatric wards in European countries. BM 2000;320:79-82.

10 ‘ Jong GW, Vulto AG, de Hoog M, et al. Unapproved and off-label use of drugs in a children's hospital. N Engl J Med 2000;343: 1125

11 't Jong GW, Vulto AG, de Hoog M, et al. A survey of the use of off-label and unlicensed drugs in a Dutch children's hospital. Pediatrics 2001;108:1089-93.

12 Bücheler R, Schwab M, Mörike K, et al. Off label prescribing to children in primary care in Germany: retrospective cohort study. BM 2002;324:1311-12.

13 Schirm E, Tobi $\mathrm{H}$, de Jong-van den Berg LTW Unlicensed and off-label drug use by children in the community: cross sectional study. BM 2002;324:1312-13.

14 't Jong GW, Eland IA, Sturkenboom MCJM, et al. Unlicensed and off-label prescription of drugs to children: population based cohort study. BM 2002;324:1313-14.

15 Royal College of Paediatrics and Child Health, and Neonatal and Paediatric Pharmacists Group. www.rcpch.ac.uk/ publications/formulary_medicines/ Unlicensed_Medicines.pdf.

16 Royal College of Paediatrics and Child Health, and Neonatal and Paediatric Pharmacists Group. Medicines for children. London: RCPCH Publications Ltd on behalf of the RCPCH and NPPG, 1999

17 Sedrati M, Arnaud P, Fontan J-E, et al. Splitting tablets in half. American Journal of Healthcare Pharmacy 1994;13:205-6.

18 Horn LW, Kuhn RJ, Kanga JF. Evaluation of the reproducibility of tablet splitting to provide accurate doses for the pediatric population. J Pediatr Pharm Practice 1999:4:38-42.

19 Woods DJ. Extemporaneous formulations - problems and solutions. In: Choonara I, Nunn AJ, eds. Paediatric and perinatal drug therapy. Liverpool, UK: Royal Liverpool Children's NHS Trust, 1997.

20 Boseley S. EU loophole sends drug prices soaring. Guardian 24 June 2002.

21 Medicines Control Agency. Rules and guidance for pharmaceutical manufacturers and distributors 1997. London: HMSO, 1997.

22 Anonymous. Boots pharmacist and trainee cleared of baby's manslaughter, but fined for dispensing a defective medicine. Pharm J 2000;264:390-2.

23 Royal College of Paediatrics and Child Health and Neonatal and Paediatric Pharmacists Group. www.rcpch.ac.uk/ publications/formulary_medicines.

24 European Commission. http:// pharmacos.eudra.org/F2/pharmacos/docs/ Doc2002/feb/cd_pediatrics_en.pdf.

25 Anonymous. France assesses paediatric needs. SCRIP No 2738, 17 April, 2002:7

26 Shirkey $\mathbf{H}$. Therapeutic orphans. J Pediatr 1968;72:119-20. 